\title{
Universo afetivo-semiótico de adolescentes em medida socioeducativa de internação
}

\author{
Gleicimar Gonçalves Cunha ${ }^{1}$ \\ ORCID: 0000-0001-7396-8563 \\ Maria Cláudia Santos Lopes de Oliveira ${ }^{1}$ \\ ORCID: 0000-0002-6089-3379 \\ Ângela Uchoa Branco ${ }^{1}$ \\ ORCID: 0000-0002-6127-1707
}

\section{Resumo}

O Estatuto da Criança e do Adolescente (BRASIL, 1990) afırma o compromisso compartilhado por Estado, família e sociedade quanto à proteção dos direitos das crianças e jovens brasileiros. 0 adolescente que comprovadamente praticou ato infracional, após o devido processo, deve cumprir medidas socioeducativas, as quais visam a promover seu desenvolvimento e integração social. Essa orientação para o trabalho pedagógico social pressupõe uma abordagem criminológica crítica. A criminalização da pobreza, no entanto, é uma característica histórica e ideologicamente enraizada na cultura brasileira. Neste artigo, que compreende uma elaboração teórica inspirada em pressupostos da criminologia crítica, em especial no conceito de criminalização da pobreza, e de contribuições da psicologia cultural, foi analisado o universo afetivo-semiótico que impregna as vidas dos adolescentes durante o período em que cumprem medida socioeducativa de internação. Como material ilustrativo das reflexões teóricas, foram contempladas narrativas orais e crônicas escritas a partir de uma experiência de rodas de conversa com adolescentes de uma Unidade de Internação do Distrito Federal/Brasil. Esse material, recolhido em contexto de formação profissional de psicólogos (estágio curricular supervisionado), evidencia que o trabalho semiótico operado pelo sistema socioeducativo se desloca da educação, enquanto prática orientada para a emancipação e a construção de outras possibilidades de futuro, de novas trajetórias biográficas, para o engendramento da periculosidade dos adolescentes. Nessa semiosfera, os signos indiciaram crenças depreciativas e condenatórias. As rodas de conversa revelaram-se espaços favoráveis à superação do estigma de bandido que a criminalização da pobreza, em particular do adolescente pobre, impõe sobre o jovem alcançado pela justiça.

\section{Palavras-chave}

Criminalização da pobreza - Socioeducação - Psicologia cultural - Crenças - Semiosfera.

1 - Universidade de Brasilia, DF, Brasil. Contato: Contatos: gleicipsi@gmail.com; mcsloliveira@gmail.com; branco.angela@gmail.com. 


\section{Affective-semiotic universe of adolescents within restrictive of freedom socio-educational sanction}

\section{Abstract}

The Statute of Child and Adolescent (BRAZIL, 1990) affirms the shared responsibility of the State, families and society regarding the protection of Brazilian children's and youth's rights. After the due process, adolescents who have provenly committed illegal acts are submitted to a set of social-educational measures which aim at promoting his/her development and full social integration. The guidelines for such social pedagogical work presuppose a critical criminology approach. Nevertheless, criminalization of poverty is a historic and ideological rooted feature in Brazilian culture. Based on the theoretical framework of critical criminology, more specifically on the concept of criminalization of poverty, and on cultural psychology, this paper analyzes the affective-semiotic universe that pervades the lives of adolescents who are complying with internment socio-educational measures. As an illustration of the theoretical elaborations, we have analyzed written chronicles and oral narratives produced by adolescents who participated in a dialogue circle in a detention center in Brasilia, Brazil. This material was obtained within supervised training activities held by undergraduate Psychology students and evidences the semiotic work operated by socio-educational system in which education - as an emancipatory practice, oriented to the building of other future possibilities and new biographical trajectories - is substituted by an emphasis on the dangerousness of adolescents. In this semiosphere, the signs express depreciative and condemnatory beliefs. These dialogue circles turned out to be be favorable spaces that enable people to overcome the stigma attached to the youth offenders who are labeled as criminals, through the discourse of criminalization of poverty.

\section{Keywords}

Criminalization of poverty - Socio-education - Cultural psychology - Beliefs Semiosphere.

\section{Introdução}

Ao retratar o engendramento do Estado penal e o desmonte das políticas sociais condensadas na expressão Welfare State, Wacquant (2001a) oferece uma rica argumentação a respeito da importância de se desnaturalizar a delinquência, a incivilidade e a violência urbana. Para o autor, a associação desses fenômenos a regiões periféricas, pobres e degradadas das cidades, compreende um discurso acerca da origem da violência em que esta é relacionada à tolerância aos delitos e à benevolência do Estado, expressa nas 
políticas sociais, visão sintetizada nos princípios de tolerância zero ao crime, praticados nos E.U.A. (WACQUANT, 2014).

De acordo com Wacquant (2001a; 2014), a crescente adesão a tais princípios por diferentes países não é propriamente uma resposta aos índices de criminalidade, mas um modo de se lidar com as contradições do capitalismo. 0 autor demonstra que o modelo fordista de produção e acumulação de capital, fundamentado no crescimento da produtividade do trabalho, na produção em massa e na capacidade de consumo da sociedade, exigiu do Estado ferramentas político-econômico-sociais favoráveis à empregabilidade, à elevação da massa salarial global e à ampliação de benefícios e direitos sociais, na direção de um Estado de bem-estar social, condições essas que possibilitaram o acesso da população trabalhadora ao consumo. Entretanto, esse modelo mostrou-se ineficaz para conter as contradições do capitalismo.

Assim, a partir da década de 1970, quando se deu uma forte recessão econômica mundial, o capitalismo deixou de investir na produção e consumo de bens e foram forjados novos padrões de acumulação flexível do capital, modelo mais eficaz para responder à intensificação da concorrência capitalista. A consequência dessa guinada no modus operandi do capital foi o agravamento do desemprego, a precarização das condições de trabalho e a diminuição dos investimentos em políticas sociais, o que privou uma enorme massa da sociedade dos direitos fundamentais à sobrevivência. Diante disso, e para manutenção da ordem social, os Estados, enfraquecidos em seu compromisso social, fortaleceram seu aparelho de coerção e repressão dos miseráveis. Nisso consiste a crítica de Wacquant (2001a; 2014): a produção flexível implica um Estado politicamente fraco, descompromissado com a justiça social e permissivo para com as grandes corporações transnacionais e capitais especulativos, equipado para reprimir a população marginalizada.

Neste artigo, a criminalização da pobreza é tomada como um conceito relevante para compreensão do capitalismo mundial, na contemporaneidade, e sua interdependência aos ditames neoliberais e à atitude repressiva do Estado perante as populações empobrecidas. No cenário político-econômico do Brasil, em que sequer se alcançou minimamente o bem-estar social e já vive importantes retrocessos, o conceito pode contribuir para compreensão da complexa tessitura formada pela: a) condição real de pobreza e exclusão da juventude de periferia; b) dinâmicas de preconceito fundamentado sobretudo na cor da pele e na classe social; e c) produção social da marginalização, que tem como uma de suas expressões a infração juvenil.

\section{Socioeducação: a construção de uma semiosfera favorável ao desenvolvimento}

A história do cuidado às crianças e adolescentes, desde o Brasil-colônia até a Constituição de 1988, evidencia uma série de lacunas, desvios éticos e omissões, que submeteram esse público a políticas públicas que escaparam dos princípios de proteção social. Desde 1990, o Estatuto da Criança e do Adolescente (ECA), ao instituir a doutrina da proteção integral, cuida dos direitos e deveres do público infanto-juvenil, sem exceção, 
orientando o conjunto de políticas voltadas ao mesmo, regula as medidas de proteção e prevê medidas socioeducativas para adolescentes que cometeram atos infracionais.

Os princípios norteadores desse Estatuto estabelecem ações de ressocialização e impõem ao adolescente infrator a aplicação de medidas socioeducativas, como alternativa para não deixar impune o ato praticado, reparar o dano social, mas também responsabilizar e emancipar o adolescente como cidadão em desenvolvimento. 0 Estatuto concebe a infração juvenil como diferenciada do crime cometido por um adulto e prevê seis medidas socioeducativas, aplicadas de acordo com a gravidade e a frequência do ato.

Sucintamente, o ECA prevê quatro medidas socioeducativas não-privativas de liberdade: advertência, repreensão verbal pronunciada por um juiz, documentada e assinada pelas partes envolvidas; obrigação de reparar o dano, aplicada quando o ato infracional provoca danos patrimoniais, exigindo restituição ou compensação do prejuízo; prestação de serviços à comunidade, realização de tarefas gratuitas junto a entidades assistenciais e comunidade, sem prejuízo da frequência escolar ou da jornada de trabalho; e liberdade assistida, programa de acompanhamento e inclusão psicossocial do adolescente e sua família (BRASIL, 2002).

Além dessas, o ECA prescreve dois modelos de medidas socioeducativas com privação de liberdade: a semiliberdade, que impõe a permanência do adolescente em um estabelecimento socioeducativo, em geral uma residência de sua própria comunidade, no qual ele viverá em pequenos grupos, sob a supervisão de adultos, e seguirá uma rotina de atividades externas, em horários estabelecidos; e internação, que somente deve ser aplicada quando não houver outra medida mais adequada, sendo que o período máximo de internação não pode exceder a três anos. Todas as medidas socioeducativas devem obedecer aos princípios da brevidade e excepcionalidade. As duas últimas somente devem ser aplicadas quando o adolescente, pelo ato infracional cometido, ameaçou ou violentou a vítima, ou, ainda, repetiu infrações graves, ou descumpriu outra medida socioeducativa estabelecida.

Seus dispositivos legais sugerem que essas medidas têm um caráter reparador, coercitivo e educativo no que diz respeito à proteção integral e ao acesso à formação, à informação e ao desenvolvimento. Por elas, depreende-se que além de submeter-se a uma sanção justa pelo ato praticado de violação à lei, seria garantido o acesso do adolescente a oportunidades de superação de sua condição de exclusão e à formação de valores positivos, coerentes com a vida em sociedade. Contudo, o paradigma da proteção integral não conseguiu conter o agravamento da violência (inclusive institucional) que vitimiza adolescentes e jovens nos últimos anos, como atesta o Atlas da Violência 2018, organizado por Cerqueira et al. (2018).

Os sistemas socioeducativos que, nos estados e municípios, são responsáveis pela execução das medidas, parecem ainda referenciados no modelo tutelar e correcional do passado, que autoriza a violência em nome da punição. A frequente incidência de matérias na mídia reportando práticas de violações de direitos, sobretudo no interior das unidades de internação, corrobora a lógica prisional ainda vigente e evidencia a perpetuação da violência na vida desses jovens. Em geral provenientes de contextos marcados por violência, expostos a condições de vulnerabilidade e aos riscos psicossociais, os adolescentes em 
medida socioeducativa convivem com a violação de direitos desde cedo, dentre os quais está a escolarização (MILANI, 2018; RODRIGUES, 2017; TEIXEIRA, 2005). Nos dizeres de Castro e Guareschi (2008), a privação da dignidade social encaminha adolescentes à privação da liberdade individual.

Como sujeito em desenvolvimento, o adolescente convive com sistemas semióticos (VALSINER, 2012, 2014; FREIRE; BRANCO, 2016) que constituem o nicho dentro do qual seu sistema de self se organiza e transforma. No caso das instituições de internação, por exemplo, há um sistema formal, que inclui regras de funcionamento, relações hierárquicas, critérios de separação dos adolescentes, modelos de avaliação adotados pelas equipes técnicas responsáveis pelo acompanhamento do adolescente no processo de socioeducação, proposta pedagógica, dentre outros (LOPES DE OLIVEIRA; VIEIRA, 2006); e também um sistema informal, que abrange concepções, crenças e valores implícitos sobre o atendimento, como os significados acerca da adolescência, ato infracional, punição, educação, criminalidade, pobreza, dispositivos de controle do comportamento, cultura organizacional, até a própria cultura juvenil.

Nessa linha de compreensão, o trabalho semiótico operado pelo sistema socioeducativo desloca-se da educação, enquanto prática orientada para a emancipação e a construção de outras possibilidades de futuro, de novas trajetórias biográficas, para o engendramento e a reificação da periculosidade dos adolescentes. Nessa semiosfera, os signos revelam crenças depreciativas e condenatórias. As produções discursivas a partir das quais os adolescentes são subjetivados são reforçadas nos relatórios técnicos nos quais psicólogos são instados a determinar prognósticos acerca dos riscos de eventuais reiterações infracionais (BORBA; LOPES; MALFITANO, 2015; CASTRO; GUARESCHI, 2008; ESPÍNDULA et al., 2006).

Afınal, que efeitos a criminalização, também presente na cultura das instituições do sistema de socioeducação, provoca sobre as autoimagens e as trajetórias de desenvolvimento de adolescentes infratores? Como uma Unidade de Internação pode colaborar com o processo de subjetivação do adolescente em medida socioeducativa, favorecendo o desenvolvimento de uma nova compreensão de si e do mundo que o cerca, de sua autonomia e inclusão social, estando ele exposto ao aniquilamento de sua singularidade e sendo ele concebido como um criminoso não apenas porque cometeu um ato infracional, mas, antes, por ser adolescente, pobre e morador da periferia?

\section{Valores, crenças e interações sociais no âmbito da socioeducação: contribuições da Psicologia Cultural}

Branco e Borges-de-Miranda (2018) esclarecem que, além das restrições culturais, crenças e valores cultivados dentro dos contextos escolares podem operar como signos que encorajam e apoiam perspectivas de vida auspiciosas para os estudantes, ou, pelo contrário, podem gerar projetos de vida estreitos ou antissociais entre os alunos. As crenças analisadas neste artigo evidenciam uma semiosfera cujos signos, de igual modo em uma unidade de internação, sustentam a insistência em culpar os adolescentes e suas famílias por seus fracassos, classificando-os como não-educados, desviantes, criminosos e assim por diante. Nas unidades do sistema socioeducativo, os trabalhadores parecem perder de 
vista a realidade de injustiça e abandono a que tais adolescentes estão submetidos pela sociedade e pelo Estado e, ao culpabilizar as vítimas, contribuem para reforçar o desvio cometido, no lugar de procurar ativamente maneiras construtivas de superar as reais dificuldades enfrentadas pelos jovens internos, conforme demonstram Santibanez (2016); Santos (2016) e Silva (2014).

Segundo a Psicologia Cultural, crenças e valores guiam a dinâmica das relações intersubjetivas estabelecidas entre as pessoas em seus diversos contextos de vida. Nesse caso, mensagens sociais que criminalizam o pobre, por processos de canalização cultural (VALSINER, 2014), podem levar a sociedade, da qual também fazem parte os educadores sociais, a temer o adolescente infrator, em geral morador da periferia, no lugar de considerá-lo como um sujeito em situação peculiar de desenvolvimento que requer, como sinaliza o Sistema Nacional de Atendimento Socioeducativo (SINASE, 2012), ações/ interações promotoras de desenvolvimento.

De acordo com Branco (1993), a canalização cultural compreende um processo a partir do qual metas, regras, normas e restrições particulares, presentes em contextos específicos de vida, levam ou direcionam ações, interações e significados de interpretação em certas direções.

Valores e crenças atuam na qualidade das trocas interpessoais, entretanto, não necessariamente os sujeitos envolvidos nas interações sociais têm conhecimento disso, haja vista as incongruências entre o prescrito/dito e o executado. Não raras são as vezes em que os educadores sociais se relacionam e se comunicam com os adolescentes de modo austero e truculento. No lugar de colaborar para o desenvolvimento de valores pautados no respeito, ensinam aos adolescentes a violência e exemplificam o desrespeito (SANTIBANEZ, 2016; SANTOS, 2016; SILVA, 2014).

Existe uma estreita relação entre as práticas e as relações interpessoais estabelecidas e o sistema de crenças enraizado na cultura. De modo geral, o ato infracional cometido por adolescentes é associado a dois principais discursos ideológicos: de um lado, uma crença hegemônica, fundamentada em uma cultura meritocrática, culpabilizante e condenatória, que aparta o sujeito de suas condições sociais e culturais de vida, conferindo-lhe uma responsabilidade individual pela criminalidade; de outro, crenças fundamentadas em uma análise crítica do fenômeno a partir de uma contextualização social, cultural, econômica, política e histórica do sujeito (LOPES DE OLIVEIRA; RODRIGUES; SILVA, 2017; LOPES DE OLIVEIRA; SOUZA; SILVA, 2015; LOPES DE OLIVEIRA, 2014).

0 segundo sistema de crenças, embora aparentemente mais próximo dos princípios que sustentam a legislação referente à socioeducação, pode culminar, se mal compreendido, com o estabelecimento de relações de causalidade tão reducionistas e deterministas quanto as sugeridas pelo primeiro sistema de crenças. No caso, as causas deixariam de ser associadas ao sujeito e passariam a ser atribuídas ao que está fora do sujeito, o que, por sua vez, pode resultar em interações sociais hierarquizadas e não dialógicas. De um lado, o adolescente, vítima de uma sociedade injusta, que o levou a cometer um ou mais ato infracional. De outro, o educador social, representante do Estado, que compreende e perdoa o delito daquele. 
Concebido apenas como vítima, o adolescente pode tornar-se alvo de sentimentos e ações piedosos, que não mediam reflexão, responsabilização e sequer sua implicação subjetiva nos processos pessoais e sociocomunitários. Nesse caso, existe o risco de subtração do potencial do sujeito adolescente frente à participação, responsabilidade e transformação. Dentro de uma perspectiva que o vitimiza, ele não é auxiliado a sentir-se responsável pelo delito que cometeu. Ele é apenas a parte mais fraca (passiva, descredenciada de participação) da sociedade.

Young (1999) denomina de culturalistas e estruturalistas as perspectivas teóricas que buscam explicar o crime pela falta, seja de cultura ou de acesso a bens. Para o autor, essas abordagens negligenciam a subjetividade e a capacidade proativa dos sujeitos. As pessoas podem se opor ao que está estabelecido pela cultura. Essa compreensão alinha-se com a Psicologia cultural, que celebra a agencialidade do sujeito. Mediante processos de internalização, o que era de domínio coletivo passa a integrar a subjetividade (BRANCO, 2012; VALSINER, 2012, 2014). Contudo, o sujeito posiciona-se ativamente perante o complexo cultural do qual faz parte. Não obstante, a sociedade neoliberal e capitalista forja fetiches de consumo em larga escala, mas viabiliza sua realização apenas a uma pequena parcela da sociedade, posto que a maioria está alijada inclusive de seus direitos fundamentais. Conforme complementa Guareschi (2009), o que produz o crime é um complexo processo de tensão estabelecida entre a inclusão cultural e a exclusão social e econômica.

Tendo em vista a coexistência de, pelo menos, dois sistemas de crenças - um que criminaliza e outro que vitimiza o adolescente - depreende-se uma semiosfera socioeducativa repleta de antinomias, ambivalências, contradições e conflitos. Enfim, uma rede complexa de signos que ora pune, ora descompromete o adolescente. Não basta compreender o ato infracional a partir da complexa conjuntura estrutural e institucional que colaborou para sua produção. É fundamental resgatar o papel ativo do adolescente, capaz de rever seu comportamento e construir novos sentidos e rumos para sua existência.

Para colaborar com essas reflexões, foram tomados como elementos ilustrativos alguns indicadores construídos a partir de um serviço de atendimento psicológico em grupo a adolescentes de uma Unidade de Internação do Distrito Federal. 0 serviço aludido foi conduzido por estagiários do Curso de Psicologia, na clínica escola, de uma Universidade Particular do Distrito Federal, de modo que as autoras dispõem da autorização dos adolescentes para utilização de suas narrativas. Todos os serviços prestados no interior da clínica escola da Universidade são precedidos do recolhimento das assinaturas dos atendidos em Termos de Consentimento Livre e Esclarecido.

\section{Encontros com os adolescentes}

Com o objetivo geral de promover interações sociais pautadas no respeito mútuo, com vistas à construção de uma cultura de paz e de valorização do ser humano, no segundo semestre de 2017 foi oferecido um serviço de roda de conversas para adolescentes de uma Unidade de Internação do Distrito Federal.

Participaram desse trabalho 18 adolescentes homens em final de medida socioeducativa de internação. Dentre eles, apenas três eram menores de idade, os demais 
tinham entre 18 e 21 anos de idade. Todos residiam em bairros periféricos, à exceção de um, que morava com os avós no centro de uma região administrativa do Distrito Federal. Todos os jovens atendidos se descreviam como moradores das quebradas, o que indicia precária condição socioeconômica. Além disso, enfatiza-se que apenas dois, dentre os participantes das rodas de conversa, estavam cursando o ensino médio. Os demais encontravam-se no equivalente ao ensino fundamental.

Eles foram distribuídos em três grupos, que foram constituídos considerando-se o interesse do interno, seu horário de permanência na escola, a possibilidade de convívio e a compatibilidade de horário com os disponibilizados pela equipe responsável pelo atendimento. Apesar da composição prévia dos grupos, esses permaneceram abertos, pois à medida que as sentenças se encerravam e/ou cursos externos à Unidade eram conquistados/providenciados, alguns integrantes saíam e outros entravam.

Para a efetivação dos objetivos propostos, foram conduzidos, em cada encontro, processos dialógicos e coletivos acerca de aspectos presentes no desenvolvimento dos integrantes. Segundo Valsiner (2012), a existência humana é organizada por um complexo sistema de signos, cujos significados semióticos são socialmente construídos e pessoalmente internalizados. Esse pressuposto orientou a intervenção e colaborou para a valorização das experiências vividas pelos adolescentes e dos sentidos construídos a partir delas (sistema de crenças que constituem a cultura pessoal ${ }^{2}$ ). Buscou-se estimular a avaliação de comportamentos e signos associados a eles, visando à produção de novos sentidos, novas formas de atuação no cotidiano.

A despeito do temário previamente pensado pelos coordenadores dos grupos, esses identificavam, a cada encontro, os temas de interesse dos participantes. Esse cuidado exigiu da equipe de coordenação uma escuta psicológica atenta, sensível às ambivalências, oposições e ambiguidades inerentes à polifonia do grupo. Importante lembrar que os diálogos autênticos são necessariamente abertos. Não se sabe, de antemão, o que se deve dizer e como expressar os pensamentos ao(s) outro(s). Também não se sabe o que a outra pessoa vai entender da mensagem pronunciada, isso só pode ser intuído a partir das respostas do(s) ouvinte(s). A pessoa com quem se conversa não dispõe apenas de ouvidos para ouvir, mas também de boca para falar (MARKOVÁ, 2006).

Assim, visando ao estabelecimento de interações sociais capazes de resgatar a autoconfiança dos adolescentes, buscou-se estimular o confronto de ideias, incluindo paixões e admirações, e desapontamentos e equívocos sobre a vida. Foram adotados dispositivos favoráveis ao diálogo coletivo, como música, documentários, relatos de histórias de vida, instrumentos figurativos, técnicas de condução grupal e jogos que proporcionassem o compartilhamento de histórias, sentimentos, valores e crenças associados à vida familiar, escolar, profissional e comunitária.

Intentou-se reconhecê-los como sujeitos de necessidades, com um potencial criativotransformador muitas vezes silenciado pelo próprio Sistema Garantidor de Direitos. Os encontros visavam, nesse sentido, a estimular uma reflexão acerca da singularidade

2- Valsiner (2012) denomina por cultura pessoal os significados particulares subjetivamente construídos, a partir da mediação semiótica, no âmbito das relações intersubjetivas. 
do adolescente. Para tanto, fez-se uso da linguagem, concebida como instrumento sociocultural dialético que tanto constitui o sujeito, como o mantém conexo à cultura.

Neste artigo, para ilustrar o debate teórico, foram considerados: (a) os registros cursivos da coordenadora dos grupos sobre a participação oral dos adolescentes durante os encontros e (b) as crônicas, também redigidas pela coordenadora, a partir desses registros. Foram realizados sete encontros com cada grupo, com tempo médio de uma hora e meia de duração.

Como foram constituídos e acompanhados três grupos de adolescentes, o material referente a cada grupo foi organizado em sequência, conforme a data em que o encontro ocorreu, e, posteriormente, foram realizadas três modalidades de leitura e releitura do material. Esse foi analisado tanto intra quanto intergrupos: 1) leitura vertical, com ênfase na produção de significados de cada grupo separadamente; 2) leitura horizontal, com foco nos elementos comuns identificados nos registros de cada grupo e, depois, nos registros dos três grupos conjuntamente; e leitura transversal, ocasião em que os registros foram tratados com a lente voltada para os elementos que atravessaram todos os encontros de todos os grupos. Esse procedimento de análise dos registros e das crônicas foi inspirado na proposta de Barbato; Mieto e Rosa (2016).

\section{O que dizem os adolescentes sobre si mesmos: indícios de criminalização da pobreza}

A partir dos procedimentos de análise descritos, em particular da leitura transversal dos registros e das crônicas, foram identificados quatro eixos de reflexão comuns aos três grupos: 1) violações de direitos; 2) encarceramento; 3) olhares docentes e 4) família - os quais foram colocados em diálogo com o conceito de criminalização da pobreza e princípios da psicologia cultural.

\section{Violações de direitos}

Art. 227- É dever da família, da sociedade e do Estado assegurar à criança e ao adolescente, com absoluta prioridade, o direito à vida, à saúde, à alimentação, à educação, ao lazer, à profissionalização, à cultura, à dignidade, ao respeito, à liberdade e à convivência familiar e comunitária, além de colocá-los a salvo de toda forma de negligência, discriminação, exploração, violência, crueldade e opressão. (BRASIL, 1988).

A despeito do estabelecido pela Constituição de 1988, durante os encontros grupais, os participantes denunciaram violações sofridas no decorrer de suas trajetórias, nomeandoas como dificuldades encontradas antes e após sua entrada na Unidade de Internação. A frequência e a intensidade com que esse tema foi retratado pelos adolescentes indicam a gravidade da situação.

Dentre as denúncias de violação de direitos, apareceram em todos os encontros realizados com os três grupos: preconceito; falta de respeito; opressão; negligência e negação de acesso à educação de qualidade, lazer e profissionalização. 
Os adolescentes apresentaram inúmeras reclamações concernentes à forma como foram e são tratados pelos policiais: "O PM já chega mandando abrir as pernas, mesmo quando você tá de boa, conversando com seu parça (parceiros)”. Os relatos sugerem discriminação: "parece que nóis têm uma frase na testa dizendo que nóis é bandido, porque pode ter uma cambada de gente, mas os PM só chega em nóis”. As denúncias de truculência e rispidez com que são abordados revelam falta de respeito. Segundo os adolescentes, os policiais são agressivos: "Os PM rasgam as nossas bermudas, furam os pneus das bicicletas...”. Foram várias as falas referentes a agressões sofridas pelos adolescentes por parte de policiais, que, segundo eles, os julgam a partir da cor de sua pele, das roupas e/ou tatuagens.

Essas vozes confirmam a presença de um sistema semiótico marcado pela criminalização da pobreza. Julgados e condenados por serem pretos e usarem roupas "da periferia", os adolescentes percebem-se alvo de comportamentos preestabelecidos. Sendo que o preconceito para com eles não é prerrogativa de policiais. Quando utilizam transportes públicos, eles também enfrentam olhares de discriminação: "Foi só eu sentar no banco, para o cara que tava do lado levantar"; "Tem gente que não fala nada, só sai de perto". "Parece que a gente vai roubar todo mundo".

Ao longo do processo grupal, foi conduzida uma atividade a partir da qual os jovens tinham de escrever palavras correspondentes ao que eles gostariam que fizessem com eles. Foram indicadas as seguintes palavras: "conversar", "mais gentileza", "me tratar bem", "mais compreensão", "que acreditassem mais em nós", "mais educação" e "mais oportunidades”. Destas, depreende-se a violação de direitos básicos ao respeito, à educação, ao lazer, à profissionalização e à cultura.

Em relação à falta de profissionalização, os jovens denunciaram acesso escasso a cursos profissionalizantes e a falta de conhecimento acerca de profissões e cursos mais acessíveis a eles, o que dificulta ainda mais a entrada no mercado de trabalho.

\section{Encarceramento}

Os adolescentes foram unânimes em dizer que a internação compreende tão somente uma medida de punição, carecendo de valor educativo. Nas unidades, segundo seus depoimentos, eles não aprendem nada; estão somente privados da liberdade: "Véi, tô cansado da cadeia. Quero sair daqui"; "Esse negócio que eles chamam de quarto é uma cela"; "Se isso aqui fosse casa, eu ia comer quando eu tivesse fome"; "A Unidade é que nem cadeia, nem porta tem no banheiro"; "Não gosto que minha véia (referindo-se à mãe) vem me ver na cadeia"; "vou sair dessa vida só porque cadeia é ruim demais".

\section{Olhares docentes dirigidos aos adolescentes}

Os participantes mostraram-se insatisfeitos com a metodologia didática utilizada pelos professores, relatando a dificuldade de aprender em virtude dos recursos escassos, aulas monótonas e professores com os quais não estabelecem boas relações. A reclamação concernente à baixa qualidade da relação estabelecida com os professores foi geral entre 
os jovens. Eles denunciaram que os professores, tanto aqueles com os quais tiveram aula antes de entrarem no Sistema, quanto os de dentro da Unidade, os tratavam com desprezo e indiferença, manifestando preconceitos e descrença quanto à capacidade deles de aprender. Salvo raras exceções, os professores sequer os cumprimentavam ao entrar em sala de aula; outros teciam comentários como: "vocês não são ninguém e seus filhos também não serão"; "vocês estão aqui justamente porque não querem nada com a dureza"; "aproveitem essa escola, porque a gente sabe que quando saírem daqui vocês não voltarão pra sala de aula”; "mente vazia é mente assassina”. Essas queixas compreendem não apenas o descontentamento dos adolescentes, na posição de estudantes, mas também a rede de significações que sustenta as práticas educacionais e as relações interpessoais vivenciadas no interior das escolas, particularmente em unidades de internação.

\section{Família - contexto de afeto e proteção}

Embora o adolescente, de modo geral, restrinja sua família à pessoa de sua mãe, percebeu-se, em relação a esse contexto de desenvolvimento, um forte valor. Falas como: "quando você está lá dentro é só você e sua mãe" e "quero trabalhar para comprar uma casa para minha mãe” indicam que a família, particularmente a mãe, é, para eles, o outro social mais significativo, com quem mantêm profundo vínculo afetivo; haja vista a elevada quantidade de adolescentes com o nome da mãe tatuado em seus corpos (dentre os 18 adolescentes atendidos, 6 tinham uma tatuagem com o nome da mãe e/ou um desenho em homenagem a ela).

Neste trabalho, o adolescente é concebido como um sujeito ativo em seu processo de desenvolvimento. Ele negocia com outros, que lhe impõem limitações e canalizações dos sentidos que comporão seu self. Neste caso, vê-se como favorável a participação da família (mãe) no desenvolvimento do jovem, quando essa incentiva o adolescente. Diferente dos olhares depreciativos retratados anteriormente, as falas de algumas mães, referenciadas pelos adolescentes no decorrer dos atendimentos grupais, demonstram concepções e expectativas positivas em relação ao sujeito: "Parabéns, continue assim, e dê mais valor para si mesmo e para todos que estão a sua volta e mostre para eles que ainda dá tempo de mudar"; "Você é um rapaz trabalhador. Sai dessa vida enquanto há tempo"; "Você não precisa ficar nessa vida".

0 receio de morrer, retratado pelos adolescentes em associação à morte de alguns familiares, também sinaliza o quanto a família é importante para eles: "Meu maior medo é perder mais alguém da minha família e perder a vida”; "[...] meu primo morreu”; "Coloquei em minhas tristezas de não estar com a família e ter perdido meu pai e não ir no enterro dele"; "Eu não me dava bem com meu pai, mas quero vingar a morte dele".

"Eu era dessa vida, mas não sou mais, isso deixou minha mãe triste, meu tio ainda está e ninguém gosta. Tenho quatro irmãos. Eu que sou a ovelha negra lá de casa. Isso causa desunião na família": essa fala confırma a importância da família no processo de construção e negociação de significados para o sujeito adolescente. 


\section{Crenças e práticas pedagógicas na escola e na socioeducação}

Os relatos analisados na seção anterior, à luz da perspectiva de Wacquant (2001a, 2001b, 2014) podem ser concebidos como indicativos da criminalização do pobre. Eles denunciam a crença na periculosidade do jovem infrator e a consequente inviabilidade de sua recuperação social. Também indicam a predominância de crenças e representações que individualizam e naturalizam fenômenos que deveriam estar sendo compreendidos e enfrentados conforme sua natureza complexa e multifacetada. Isso confirma a importância de se desnaturalizar os discursos referentes à delinquência, à violência urbana, à pobreza e às incivilidades.

Para Valsiner (2012), as pessoas somente podem ser compreendidas no âmbito das relações com outras pessoas, os objetos e o mundo simbólico em que vivem. A internalização das relações e mensagens sociais por parte da pessoa em desenvolvimento acontece por meio dos signos e afetos que circulam tanto no nível interpessoal quanto intrapsicológico. Em outras palavras, a cultura e os processos afetivo-semióticos desempenham papel fundamental no desenvolvimento do sujeito, princípio que evidencia a gravidade do cenário descrito pelos adolescentes.

Ao abordar a mediação semiótica no âmbito interpessoal, Valsiner (2012) enfatiza o risco das armadilhas semióticas ou declarações ideológicas para os interlocutores. Nessa perspectiva, o relato dos adolescentes a respeito do tratamento dos professores, além de ilustrar a criminalização da pobreza, particularmente do adolescente pobre, sugere a inferioridade do estudante e, em contrapartida, a superioridade do professor. Capturam simbolicamente o self do adolescente em uma rede de culpa e desvalia que em nada colabora para o processo de socialização do sujeito.

Por outro lado, apesar da armadilha semiótica indicada por Valsiner (2012), manifestada aqui em práticas discursivas estabelecidas com os adolescentes por professores do sistema, reconhece-se que os recursos subjetivos dos adolescentes lhes permitem definir o impacto das canalizações culturais dos contextos dos quais fazem parte, como a escola. Portanto, a despeito do caráter pejorativo das falas dos professores, admite-se que os adolescentes negociam sentidos sobre si mesmos, podendo assumir outra direção que não aquela preconizada pelos professores.

Entretanto, mesmo nessa perspectiva dialógica e dinâmica de desenvolvimento, é fundamental para o processo de construção do self do adolescente a internalização de mensagens culturais positivas a seu respeito. Não se sabe que tipo de construção narrativa o sujeito fará a partir das vozes internalizadas. Sabe-se, por outro lado, que existe uma dimensão política das forças sociais e uma natureza social do sistema semiótico no qual ocorre o desenvolvimento, portanto, cabe ao professor rever suas concepções, visando à construção de discursos mais favoráveis à mediação dos processos de ensinoaprendizagem, a partir dos quais o estudante também constrói seu self.

Matusov (2018) colabora com essa reflexão ao abordar a pedagogia dialógica ontológica crítica. Segundo o autor, cabe à educação - com destaque aqui da socioeducação - promover um exame crítico do eu, da vida e do mundo dos sujeitos em desenvolvimento, incluindo o sentido da própria educação. Ela deve, por processos dialógicos protagonizados 
por estudantes e professores, revelar e analisar valores (vigentes, dominantes, latentes, conflitantes), colocando-os em contato com valores alternativos, testando alguns e desconstruindo outros. Matusov (2018) considera que esse processo pode tornar o currículo de aprendizagem pessoalmente mais relevante e atraente para os estudantes.

0 autor admite, entretanto, que essa proposta requer coragem dos envolvidos, pois pode colocá-los em estado de tensão, uma vez que os valores têm grande importância afetiva para cada pessoa. Desconstruí-los pode ser problemático, afinal, os valores definem as pessoas e suas relações com alteridades. Tanto seu reconhecimento, como sua expressão podem ser ofensivos seja para quem os identifica em si, como para aquele que testemunha sua apresentação. A pedagogia dialógica ontológica crítica pode desencadear, em seus participantes, crises existenciais indesejáveis, e/ou perturbar seus relacionamentos interpessoais (MATUSOV, 2018). Mas em um contexto afetivo de cuidado e respeito, os posicionamentos dialógicos podem permitir processos de verdadeira mudança em relação a valores e projetos de vida, objetivo da própria socioeducação.

Vale destacar que o exercício do direito à escolarização parece representar para o adolescente uma segunda sentença, que se refere não somente ao ato infracional cometido, mas também ao próprio fracasso escolar e à afirmação de que ele é o responsável pelas condições que o afastaram da escola. Essa interpretação confirma a importância do trabalho de atendimento grupal junto a adolescentes em medida de socioeducação, no qual esses podem falar sobre e negociar novos significados acerca das experiências escolares, entre outras, e torna legítima a proposta de uma pedagogia dialógica, ontológica crítica, apesar de seu caráter inerentemente arriscado e inseguro. Pela importância atribuída aos valores, compreende-se que essa perspectiva se alinha com o trabalho promovido junto aos adolescentes.

Nos atendimentos grupais, são possíveis a produção e a análise das narrativas que compõem o contexto de desenvolvimento do sujeito. Esse espaço de interações sociais proporcionado aos adolescentes tem se revelado favorável ao debate e à negociação intersubjetiva, especialmente daquelas vozes que insistem em culpar o adolescente pelo fracasso do passado e condená-lo a um futuro sem perspectivas, ou seja, também fracassado.

Enquanto signo mediador da relação professor-aluno, a autoridade docente pode tanto colaborar para a emancipação do estudante quanto subjugá-lo. Essa reflexão é também especialmente legítima para o agente socioeducativo, frente a quem, em geral, o adolescente permanece com as mãos para trás e a cabeça inclinada para baixo, dando a entender que aceitou a relação de poder na qual ele é o sujeito submisso e sem voz.

Como uma instituição social, regida por princípios e regras expressos em uma organização curricular, de tempo e espaço, a escola não é neutra. Ela compreende diferentes interesses e forças que incidem em seu interior, de modo explícito ou oculto, com destaque dos modelos políticos e econômicos vigentes; da cultura familiar dominante; dos fetiches e demandas sociais, associados à cultura de consumo (CAMPOS; SOUZA, 2003); e das concepções teórico-filosóficas acerca do desenvolvimento, da aprendizagem, do ensino, da avaliação e dos papéis de professor e estudante subjacentes às práticas pedagógicas. Dentre outros aspectos, esses elementos atravessam as práticas sociais e pedagógicas, impactando os processos de ensino e aprendizagem e de coconstrução do self daqueles que vivem nesse contexto institucional. 
Universalizada como instituição responsável pela socialização e capacitação intelectual do sujeito, a escola assumiu, desde o advento do capitalismo, um compromisso de formação para o mercado de trabalho. Nesse caso, ficou imputado ao professor o dever de conduzir o processo de ensino e aprendizagem de modo que o estudante tenha condições de responder consonantemente às demandas que lhe são dirigidas na vida social, sejam elas de produtividade e/ou de consumo. Portanto, a prática pedagógica, a despeito do ideário intelectual que rege grande parte do ofício docente, está condicionada a interesses político-econômicos neoliberais. Inserida no sistema socioeducativo, a escola acaba por abrigar sujeitos junto aos quais não logrou êxito. Às funções sociais e econômicas da escola, no contexto da socioeducação, são agregadas, ainda, outras funções, não apenas de caráter preventivo e de inclusão (segundo princípios do capitalismo).

No cenário socioeducativo, a instituição deve ir além e colaborar com o processo de responsabilização do adolescente perante seu ato infracional e com a promoção de valores pró-sociais, os quais apenas poderão ser gerados a partir da reflexão autônoma dos sujeitos. Esse ensejo representa, porém, um paradoxo: de um lado, compulsoriamente, os adolescentes são reinseridos em um sistema (educativo) que os havia expelido; de outro, observa-se a manutenção de concepções ainda pautadas em olhares acusatórios e depreciativos que, além de evidenciarem a criminalização, culminam com a patologização e culpabilização do estudante por seu fracasso (como indicam aquelas falas resgatadas pelos adolescentes no âmbito dos atendimentos em grupos).

Levando em conta que as crenças, valores e expectativas dos adultos (especialmente dos educadores) transparecem especialmente através da comunicação não-verbal e da qualidade afetiva das relações estabelecidas por estes com as crianças e adolescentes, e também considerando o significativo poder do afeto, do exemplo e das profecias autorrealizadoras (BRANCO, 2018), é fácil concluir que a tarefa do docente no contexto da socioeducação é ainda mais complexa e desafiadora do que aquela assumida pelos educadores no contexto das escolas em geral. Cabe a ele planejar suas aulas de maneira a motivar os alunos, proporcionando oportunidades para o debate e a reflexão sobre as múltiplas vozes, crenças valores presentes na cultura e na constituição do sentido de self de cada um. Para além das funções acadêmicas, ambientes educativos constituemse em espaço privilegiado de convivência entre pessoas e um ponto de referência para o processo de constituição identitária e de formação do cidadão, especialmente no que tange à construção de valores e crenças.

Não obstante, durante as rodas de conversa, os adolescentes descreveram a internação, contexto no âmbito do qual a escolarização ocorre quando se encontram em medida socioeducativa com privação de liberdade, como sinônimo de encarceramento. Esse relato articula-se ao proposto por Goffman (1974, p. 11), para quem:

[...] instituição total pode ser definida como um local de residência e trabalho onde um grande número de indivíduos com situação semelhante, separados da sociedade mais ampla por considerável período de tempo, leva uma vida fechada e formalmente administrada. 
Parecem incompatíveis com o objetivo de promoção da autonomia os modos pelos quais funcionam as medidas socioeducativas com privação de liberdade, sobretudo de internação. Goffman (1974) denominou de mortificação do eu o processo pelo qual a instituição total, por meio da disciplina, modifica a percepção de si e do outro, pelo sujeito. Para o autor, esse processo serve para a docilização das pessoas ao funcionamento institucional. Retira-se do sujeito sua autonomia, capacidade de decisão e sua autodeterminação, pelo controle de todas as atividades por parte da equipe institucional. Em uma unidade de internação não é possível fazer qualquer deslocamento, inclusive do dormitório para a escola e refeitório, sem o acompanhamento de um agente de segurança. Não é permitido ao adolescente levar para o dormitório lápis, caneta, caderno. Tem-se horário para o banho, o cigarro (quando esse é admitido), o sol, os lanches e as refeições. Enfim, a vida dentro de uma unidade de internação caracteriza-se pelo controle, vigilância, atitudes fundamentadas no paradigma da desconfiança, da culpa e consequente disciplina.

A insatisfação dos adolescentes participantes do projeto confırma a hipótese de Wacquant (2001a, 2014): a solução dos altos índices de criminalidade não virá pelo encarceramento. Ao contrário, exige a adoção de medidas alternativas e a conexão de políticas penais e sociais do Estado, com vistas a ações preventivas em relação à violência, não simplesmente repressivas, e ações instigadoras da prossociabilidade e resolução pacífica de conflitos.

\section{Considerações finais}

As Unidades de Internação, conforme estabelecido no SINASE (2012), são espaços de execução da socioeducação, comprometidas com a responsabilização, emancipação, cidadania, enfim, promoção de desenvolvimento. Segundo as vozes consideradas neste artigo, entretanto, muitos profissionais, sob a responsabilidade dos quais se encontram as ações desenvolvidas no âmbito das Unidades de Internação, dirigem aos adolescentes olhares preconceituosos, assentados em crenças que os criminalizam e os silenciam (COELHO, 2015; MILANI, 2018; VIDAL, 2017; VIEIRA, 2015; REBOUÇAS, 2015).

Valsiner (2012) esclarece que as práticas socioculturais medeiam os processos de desenvolvimento, da formação da autoimagem e de significações acerca de si. Portanto, apesar do caráter ilustrativo das narrativas contempladas neste artigo, enfatiza-se, em função da relevância da atuação dos profissionais junto aos adolescentes em medida socioeducativa, a importância de sua formação continuada. Para melhor investigar essa questão, uma das autoras deste artigo, em seu processo de doutorado, propôs-se a investigar o sistema de crenças dos agentes socioeducativos que atuam em unidades de internação, com foco em seus princípios e relações com as práticas a ele associadas.

Identifica-se, por um lado, a necessidade de implementação de uma política de educação permanente para os profissionais que operacionalizam a socioeducação. A partilha, circulação e troca de concepções, valores, crenças, emoções e afetos experimentados no cotidiano do trabalho, no âmbito da socioeducação, podem colaborar para a construção de conhecimentos mais congruentes com a doutrina de proteção integral e a visão do sujeito de direitos incorporada ao ECA, uma vez que tensões e contradições poderão ser deflagradas. 
As narrativas analisadas neste artigo confirmam que o compromisso com o desenvolvimento do adolescente em medida socioeducativa exige cuidar do desenvolvimento profissional dos educadores, como primeira estratégia para qualificar o atendimento. Empoderar e capacitar esses profissionais é condição para que eles possam mediar o desenvolvimento dos adolescentes, contribuindo para a construção de projetos de vida que os preservem da vivência infracional.

Além da formação continuada dos profissionais, a questão anunciada anteriormente acerca dos efeitos da criminalização do adolescente pobre em suas autoimagens e trajetórias de desenvolvimento confirma a importância das metodologias de grupo, como a que se experimentou na intervenção tomada como exemplo das considerações teóricas deste artigo.

Embora os princípios do SINASE convirjam com a ideia de equipes multi- e interdisciplinares, que interajam ativamente na interpretação e condução dos casos, as dificuldades de pessoal, e outras inerentes ao sistema, vêm tornando esses espaços dialógicos e colaborativos cada dia mais escassos. Instados a construir relatórios, os especialistas socioeducativos - pedagogos, psicólogos e assistentes sociais - acabam se restringido a atendimentos individuais (RODRIGUES, 2017).

Tornar o diálogo grupal uma prática cotidiana permitirá que, com o tempo, esse deixe de ser apenas um contexto de reclamações e denúncias das insatisfações relativas a uma realidade dura e aparentemente imutável, para transformar o grupo em espaço de produção de novidades, de solução de problemas e de transformação da realidade, o que se torna possivel a partir da construção de vozes mais críticas, conscientes e reflexivas.

No que se refere aos adolescentes, garantir-lhes a oportunidade de falar sobre si, ou seja, narrar suas trajetórias e conhecer outras histórias por vezes semelhantes às suas em ambiente respeitoso e acolhedor, pode favorecer a reflexão e reorganização interna, uma vez que a narrativa compreende uma ferramenta de organização autoepistêmica da experiência particular/subjetiva e coletiva/social (DAIUTE, 2014). Por meio da troca dialógica de ideias e experiências, o sujeito pode recuperar os elementos que habitam sua memória e constituem seu self, externalizando e ressignificando o que foi internalizado, na busca de novas trajetórias de vida.

As rodas de conversa revelaram-se espaços favoráveis à superação do estigma de bandidos que a criminalização da pobreza, em particular do adolescente pobre, impõe sobre a maioria dos adolescentes alcançados pela justiça.

Seja para os profissionais ou adolescentes, espaços coletivos de trocas podem configurar-se como um motor de efetiva transformação sistêmica da execução das medidas socioeducativas. Para além de seus benefícios pessoais, podem mobilizar estudos, problematizações e investigações acerca da socioeducação, implicando seus responsáveis e público atendido e colaborando com a revisão dessa semiosfera. 


\section{Referências}

BARBAT0, Silviane; MIETO, Gabriela Sousa de Melo; ROSA, Alberto. 0 estudo da produção de significados em interações. Metodologias qualitativas. In: LOPES DE OLIVEIRA, Maria Cláudia Santos et al. (org.). Psicologia dos processos de desenvolvimento humano: cultura e educação. Campinas: Alínea, 2016. p. 89-113.

BORBA, Patrícia Leme de Oliveira; LOPES, Roseli Esquerdo; MALFITANO, Ana Paula Serrata. Trajetórias escolares de adolescentes em conflito com a lei: subsídios para repensar políticas educacionais. Ensaio, Rio de Janeiro, v. 23, n. 89, p. 937-963, dez. 2015.

BRANCO, Ângela Uchoa. Metacommunication, microgenesis, and ideographic science: the study of meaning-construction processes. In: SALVATORE, Sérgio; GENNARO, Alessandro; VALSINER, Jaan (ed.). Making sense of infinite uniqueness. Charlotte: Age, 2012. p. 109-132.

BRANCO, Ângela Uchoa. Sociogênese e canalização cultural: contribuições à análise do contexto das salas de aula. Temas em Psicologia, Ribeirão Preto, v. 1, n. 3, p. 9-17, dez. 1993. Disponível em: http://pepsic. bvsalud.org/scielo.php?script=sci_arttext\&pid=S1413-389X1993000300003\&lng=pt\&nrm=iso. Acesso em: 19 jan. 2019.

BRANCO, Ângela Uchoa. Values, education and human development: the major role of social interactions' quality within classroom cultural contexts. In: BRANCO, Ângela Uchoa; LOPES-DE-OLIVEIRA, Maria Cláudia Santos (ed.). Alterity, values, and socialization: human development within educational contexts. Cham: Switzerland, 2018, p. 31-50.

BRANCO, Ângela Uchoa; BORGES-DE-MIRANDA, Theresa. Social dynamics and students' developmental perspectives within a school located in a poor urban community in Brasilia. In: BRANCO, Ângela Uchoa; LOPES-DE-OLIVEIRA, Maria Cláudia Santos (ed.). Alterity, values, and socialization: human development within educational contexts. Cham: Springer, 2018. p. 131-148.

BRASIL. Constituição (1988). Constituição da República Federativa do Brasil. Organizado por Cláudia Brandão de Oliveira. Rio de Janeiro: Roma Victor, 2002.

BRASIL. Estatuto da Criança e do Adolescente: Lei federal nº 8069, de 13 de julho de 1990. Rio de Janeiro: Imprensa Oficial, 2002.

CAMPOS, Cristiana Caldas Guimarães de; SOUZA, Solange Jobim. Mídia, cultura do consumo e constituição da subjetividade na infância. Psicologia, Brasília, DF, v. 23, n. 1, p. 12-21, mar. 2003. Disponível em: http://www.scielo.br/scielo.php?script=sci_arttext\&pid=S1414-98932003000100003\&lng=en\&nrm=i so. Acesso em: 20 jan. 2019.

CASTRO, Ana Luiza de Souza; GUARESCHI, Pedrinho. Da privação da dignidade social à privação da liberdade individual. Psicologia \& Sociedade, Porto Alegre, v. 20, n. 2, p. 200-207, ago. 2008. Disponível em: http://www.scielo.br/scielo.php?script=sci_arttext\&pid=S0102-71822008000200007\&lng=en\&nrm =iso. Acesso em: 20 jan. 2019. 
CERQUEIRA, Daniel et al. Atlas da violência 2018. Rio de Janeiro: IPEA: Fórum Brasileiro de Segurança Pública, 2018.

COSTA, Daniela Lemos Pantoja Coelho de Oliveira. As adolescentes e a medida socioeducativa de internação: rompendo o silêncio. 2015. 176 f. Dissertação (Mestrado em Processos de Desenvolvimento Humano e Saúde) - Universidade de Brasília, Brasília, DF, 2015.

DAIUTE, Colette. Narrative inquiry: a dynamic approach. New York: Sage, 2014.

ESPINDULA, Daniel Henrique Pereira et al. "Perigoso e violento": representações sociais de adolescentes em conflito com a lei em material jornalístico. Psicologia, São Paulo, v. 7, n. 2, p. 11-20, dez. 2006. Disponível em: http://pepsic.bvsalud.org/scielo.php?script=sci_arttext\&pid=S1676-73142006000200003\&lng=pt \&nrm=iso. Acesso em: 18 jan. 2019.

FREIRE, Sandra Ferraz de Castillo Dourado; BRANCO, Ângela Uchoa. A teoria do self dialógico em perspectiva. Psicologa, Brasília, DF, v. 32, n. 1, p. 25-33, mar. 2016. Disponível em: http://www.scielo.br/scielo. php?script=sci_arttext\&pid=S0102-37722016000100025\&lng=en\&nrm=iso. Acesso em: 21 jan. 2019.

GOFFMAN, Erving. Manicômios, prisões e conventos. São Paulo: Perspectiva, 1974.

GUARESCHI, Pedrinho. Psicologia social crítica como prática de libertação. Porto Alegre: Edipucrs, 2009.

LOPES DE OLIVEIRA, Maria Cláudia Santos. Da medida ao atendimento socioeducativo: implicações conceituais e éticas. In: PAIVA, Ilana Lemos de; SOUZA, Candida; RODRIGUES, Daniela Bezerra (org.). Justiça juvenil: teoria e prática no sistema socioeducativo. Natal: UFRN, 2014. p. 79-99.

LOPES DE OLIVEIRA, Maria Cláudia Santos; RODRIGUES, Dayane Silva; SILVA, Nilcea Moreno. Descortinando narrativas de professores sobre adolescentes e socioeducação: desafios para a ação socioeducativa. In: BISINOTO, Cynthia. Docência na socioeducação: a experiência de um processo de formação continuada. Brasília, DF: FUP-UnB, 2017. p. 55-88.

LOPES DE OLIVEIRA, Maria Cláudia Santos; SOUZA, Tatiana Yokoy; SILVA, Samuel Costa. Socioeducação: práticas e metodologias de atendimento em meio fechado. In: BRASIL. Secretaria de Direitos Humanos da Presidência da República; Secretaria Nacional de Promoção dos Direitos da Criança e do Adolescente. Coordenação Geral do Sistema de Atendimento Socioeducativo. Matriz de formação do Sistema Nacional de Atendimento Socioeducativo (SINASE): coletânea de artigos. Brasília, DF: UnB, 2015. p. 203-228.

LOPES DE OLIVEIRA, Maria Claudia Santos; VIEIRA, Alessandra Oliveira Machado. Narrativas sobre a privação de liberdade e o desenvolvimento do self adolescente. Educação e Pesquisa, São Paulo, v. 32, n. 1, p. 67-83, abr. 2006. Disponível em: http://www.scielo.br/scielo.php?script=sci_arttext\&pid=S151797022006000100005\&lng=en\&nrm=iso. Acesso em: 17 jan. 2019.

MARKOVÁ, Ivana. Dialogicidade e representações sociais: as dinâmicas da mente. Petrópolis: Vozes, 2006. 
MATUSOV, Eugene. Chronotopic analysis of values in critical ontological dialogic pedagogy. In: BRANCO, Ângela Uchoa; LOPES DE OLIVEIRA, Maria Cláudia Santos (ed.). Alterity, values, and socialization: human development within educational contexts. Cham: Springer, 2018. p.1-29.

MILANI, Janaina Ohlweiler. A educação escolar como medida socioeducativa de adolescentes em conflito com a lei: uma arqueologia de suas condições de possibilidade. 2018. 134 f. Dissertação (Mestrado em Educação) - Universidade Federal de Grande Dourados, Grande Dourados, 2018.

REBOUÇAS, Fernanda Pinheiro. 0 processo de responsabilização socioeducativa: da medida à responsabilidade. 2015. 122 f. Dissertação (Mestrado em Processos de Desenvolvimento Humano e Saúde) - Universidade de Brasília, Brasília, DF, 2015.

RODRIGUES, Dayane Silva. Grupo como dispositivo socioeducativo-dialógico: reflexões sobre uma intervenção com adolescentes em meio aberto. 2017. 246 f. Tese (Doutorado em Processos de Desenvolvimento Humano e Saúde) - Universidade de Brasília, Brasília, DF, 2017.

SANTIBANEZ, Dione Antônio de Carvalho de Sousa. Sujeição criminal e inclusão marginal no sistema socioeducativo: uma análise qualitativa das percepções de agentes do meio aberto e fechado. 2016. 205 f. Tese (Doutorado em Sociologia) - Universidade Federal de Goiás, Goiânia, 2016.

SANTOS, Ascêncio Franco. Constituição dos adolescentes infratores nos discursos da mídia e nas artes de governo no sistema socioeducativo de Cáceres-MT. 2016. 123 f. Dissertação (Mestrado em Educação) - Universidade do Estado de Mato Grosso, Cáceres, 2016.

SILVA, Amanda Santos. De menor infrator ao adolescente em conflito com a Lei: um estudo sobre 0 sistema socioeducativo. 2014. 120 f. Dissertação (Mestrado em Ciências Sociais) - Universidade Federal da Bahia, Salvador, 2014.

SINASE. Sistema Nacional de Atendimento Socioeducativo. Brasília, DF: Presidência da República: Secretaria Especial dos Direitos Humanos, 2012.

TEIXEIRA, Maria de Lourdes Trassi. Até quando? 0 adolescente e o futuro: nenhum a menos. Brasília, DF: Conselho Federal de Psicologia, 2005.

VALSINER, Jaan. An invitation to cultural psychology. London: Sage, 2014.

VALSINER, Jaan. Fundamentos da psicologia cultural: mundos da mente, mundos da alma. Trad. e revisão técnica Ana Cecília de Sousa Bastos. Porto Alegre: Artmed, 2012.

VIDAL. Lívia de Souza. A justiça restaurativa no sistema socioeducativo: análise de uma experiência. 2017. 157 f. Dissertação (Mestrado em Educação) - Universidade Federal Fluminense, Rio de Janeiro, 2017.

VIEIRA, Márcia Marques. A socioeducação na percepção do agente socioeducador: um estudo no Distrito Federal. 2015. 121 f. Dissertação (Mestrado em Psicologia) - Universidade Católica de Brasília, Brasília, DF, 2015. 
WACQUANT, Loïc. As prisões da miséria. Rio de Janeiro, Jorge Zahar, 2001a.

WACQUANT, Loïc. Marginalidade, etnicidade e penalidade na cidade neoliberal: uma cartografia analítica. Tempo Social, São Paulo, v. 26, n. 2, p. 139-164, dez. 2014. Disponível em: http://www.scielo.br/scielo. php?script=sci_arttext\&pid=S0103-20702014000200009\&Ing=en\&nrm=iso. Acesso em: 22 jan. 2019.

WACQUANT, Loïc. Punir os pobres: a nova gestão de miséria nos Estados Unidos. Rio de Janeiro: Instituto Carioca de Criminologia F. Bastos, 2001b.

YOUNG, Jock. The exclusive society: social exclusion, crime and difference in late modernity. London: Sage, 1999.

Recebido em: 12.02.2019

Revisado em: 25.06.2019

Aprovado em: 14.08.2019

Gleicimar Gonçalves Cunha é doutoranda no Programa de Pós-graduação em Psicologia do Desenvolvimento Humano e Escolar da Universidade de Brasília. É especialista em grupos operativos pelo Instituto de Psicologia Social Pichon-Rivière.

Maria Cláudia Santos Lopes de Oliveira é psicóloga, professora do Departamento de Psicologia Escolar e do Desenvolvimento da Universidade de Brasília. Coordenadora do Laboratório de Psicologia Cultural e do Grupo de Atenção e Investigação das Adolescências.

Ângela Uchoa Branco é professora emérita do Instituto de Psicologia da Universidade de Brasília, no Departamento de Psicologia Escolar e do Desenvolvimento. Fundadora do Laboratório de Psicologia Cultural. Bolsista de produtividade em pesquisa do CNPq por 20 anos. 